\title{
APROveitamento da Macrófita Aquática Egeria densa como Adubo ORGÂNICO ${ }^{1}$
}

\author{
Use of Aquatic Plant (Egeria densa) as an Organic Fertilizer
}

SAMPAIO, E.V.S.B. ${ }^{2}$ e OLIVEIRA, N.M.B. ${ }^{3}$

\begin{abstract}
RESUMO - Grandes massas de Egeria densa são retiradas dos lagos do sistema hidrelétrico de Paulo Afonso e seu descarte tem sido problemático. O aproveitamento como adubo orgânico foi comparado com o de esterco, em plantio de milho, irrigado, a campo. Foram comparadas as doses de 20 e $40 \mathrm{t} \mathrm{ha}^{-1}$ de matéria seca com testemunha, sem adubo. Paralelamente, foi acompanhada a decomposição do material incorporado ao solo. A massa de E. densa decompôsse rapidamente, restando menos de um terço após um mês e menos de $1 \%$ após dois meses. As adubações com E. densa e esterco incorporaram grande quantidade de nutrientes ao solo e resultaram em produção de grãos de milho $\left(3,5\right.$ a $\left.8,5 \mathrm{t} \mathrm{ha}^{-1}\right)$ e palha $\left(4,3\right.$ a $\left.8,8 \mathrm{t} \mathrm{ha}^{-1}\right)$ muito maior que a da testemunha $\left(0,3\right.$ e 1,2 $\left.\mathrm{t} \mathrm{ha}^{-1}\right)$. Em média, as produções com $E$. densa (grãos, $\left.7,7 \mathrm{t} \mathrm{ha}^{-1}\right)$ foram maiores que as com esterco $\left(4,2 \mathrm{t} \mathrm{ha} \mathrm{a}^{-1}\right)$, sem diferenças significativas entre doses, possivelmente porque a massa de E. densa libera nutrientes mais rapidamente. Os teores de metais pesados e outros elementos de $E$. densa ficaram dentro da faixa permitida para adubos orgânicos e não afetaram o milho. O aproveitamento como adubo orgânico parece recomendável.
\end{abstract}

Palavras-chave: planta aquática, planta daninha, fertilizante orgânico, nutrientes, milho.

ABSTRACT - The removal of large masses of Egeria densa out of the lakes of Paulo Afonso hydroelectric plant complex has been problematic. Their use as organic fertilizer was compared to

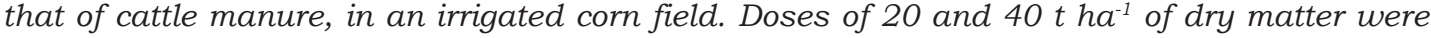
compared to a control, without fertilizer. Simultaneously, decomposition of the material in the soil was monitored. The $\boldsymbol{E}$. densa mass decomposed rapidly, with less than a third remaining after one month and less than $1 \%$ after two months. Incorporations with both $\boldsymbol{E}$. densa and manure added large quantities of nutrients to the soil and resulted in larger grain (3.5 to $\left.8.5 \mathrm{tha^{-1 }}\right)$ and straw (4.3 to $\left.8.8 \mathrm{th} \mathrm{h}^{-1}\right)$ productions than those of the control $\left(0.3\right.$ and $\left.1.2 \mathrm{tha^{-1 }}\right)$. Productions with E. densa (grain, $7.7 t^{h a^{-1}}$ ), on average, were higher than those with manure (4.2 tha $\mathrm{a}^{-1}$ ), without significant difference between doses, probably because the mass of $\boldsymbol{E}$. densa releases nutrients faster than that of manure. The content of heavy metals and other elements in the mass of $\boldsymbol{E}$. densa were within the range approved for organic fertilizers and did not affect the corn plants. Using the masses of $\boldsymbol{E}$. densa as organic fertilizer appears to be a recommendable practice.

Key words: weed, aquatic plant, organic fertilizer, nutrients, corn.

\section{INTRODUÇÃO}

Nos reservatórios do Sistema Hidrelétrico de Paulo Afonso e Itaparica, no rio São Francisco, há alguns anos, Egeria densa vem se proliferando, causando prejuízos na geração de energia, devido ao seu acúmulo nas grades de contenção das turbinas (Nascimento, 2002). E. densa é uma planta invasora, nativa da América do Sul, que tem se espalhado por

1 Recebido para publicação em 29.10.2004 e na forma revisada em 1.4.2005.

2 Prof. Dr., Universidade Federal de Pernambuco, Departamento de Energia Nuclear, 50740-540 Recife-PE, <esampaio@ufpe.br>; ${ }^{3}$ Bióloga, <nmboliveira@bol.com.br>. 
vários países das Américas, Eurásia, Oceania e África (Cook \& Urmi-König, 1984; Winton \& Clayton, 1996) e que causam, em muitos deles, problemas nos lagos que alimentam hidrelétricas ou que têm outros usos (Barreto et al., 2000; Corrêa et al., 2003).

Para eliminar ou controlar a invasora, no sistema do São Francisco, foram conduzidos estudos pela CHESF, em parceria com a UFRPE. Eles chegaram à conclusão de que a eliminação é extremamente dificil e que faz mais sentido aproveitar o material produzido. Dezenas de metros cúbicos de massa da planta são retiradas das grades, todos os anos, e uma quantidade muito maior cresce nos prados que se desenvolvem nos lagos até $9 \mathrm{~m}$ de profundidade. A produtividade anual nesses lagos pode superar 20 toneladas de matéria seca por ha, e os prados cobrem centenas de hectares (Nascimento, 2002).

O descarte da massa retirada das grades tem sido um problema para a CHESF. Também outras instituições, como a Prefeitura de Paulo Afonso, e proprietários de terras nas margens dos lagos têm tido dúvidas de como descartar o material retirado da limpeza dos reservatórios infestados. Uma das alternativas de uso seria a incorporação ao solo, como adubação orgânica. Para testar esta possibilidade, foi montado um experimento de campo, comparando a incorporação da massa de $E$. densa com a de esterco bovino, um adubo orgânico tradicional na região, usando o milho como cultura-teste. Neste trabalho são reportados os resultados deste estudo.

\section{MATERIAL E MÉTODOS}

A área de estudo foi um trecho da bacia hidrográfica do rio São Francisco, onde está o Complexo Hidrelétrico de Paulo Afonso, no municipio de mesmo nome $\left(09^{\circ} 21^{\prime} 42^{\prime \prime} \mathrm{S}\right.$ e $\left.38^{\circ} 16^{\prime} 19^{\prime \prime} \mathrm{W}\right)$, na Bahia, sendo constituído pelos reservatórios de Delmiro Gouveia e Apolônio Sales (Silva, 1985; Nascimento, 2002). No reservatório de Delmiro Gouveia foi recolhida uma massa fresca de $E$. densa equivalente à carga de um caminhão. O material foi posto para secar ao sol e depois ensacado, pesado e transportado para o local do plantio. Amostras foram enviadas para análises bromatológica e de nutrientes minerais, em laboratório da
Universidade Federal Rural de Pernambuco, e para análises de outros elementos, especialmente metais pesados, nos laboratórios do Centro Nacional de Energia Nuclear, em Piracicaba, e da UNESP, em Jaboticabal. O esterco bovino curtido foi recolhido de vacaria da Fundação de Apoio ao Menor (FUNDAME), em Paulo Afonso. A amostra foi enviada para análise nos laboratórios da UFRPE e da UFPE.

A semeadura foi feita em terreno da FUNDAME, a uma centena de metros da beira do reservatório de Delmiro Gouveia e cerca de $30 \mathrm{~m}$ acima do nível máximo da água. O terreno havia sido cultivado anteriormente com milho e macaxeira, até ser considerado como esgotado. O solo é um Neossolo Regolítico, raso e arenoso.

O experimento constou de cinco tratamentos, com três repetições, instalados em blocos casualizados: um controle sem adubação; incorporação de esterco bovino nas doses de 20 e $40 \mathrm{t} \mathrm{ha}^{-1}$; e incorporação da massa seca de $E$. densa, nas mesmas doses do esterco. Cada parcela, de $2,5 \times 3,0 \mathrm{~m}$, continha cinco fileiras, com aproximadamente $0,5 \mathrm{~m}$ de distância uma das outras, com cinco covas por fileira e cerca de 3-5 plantas por cova. O milho, cultivar BR- 5026 seleção IPA, foi plantado em abril e colhido seco em setembro de 2002. $\mathrm{Na}$ colheita, as plantas foram cortadas próximo ao solo e separadas em palhada e espigas, das quais foram destacados os grãos. Todo o material foi pesado, subamostrado e seco em estufa a $60{ }^{\circ} \mathrm{C}$. As plantas foram regadas esporadicamente, quando julgado necessário, para que não sofressem deficiência hídrica.

Paralelamente ao plantio, foi feito um teste da velocidade de decomposição do material seco de E. densa. Porções de $10 \mathrm{~g}$ foram colocadas em sacos de náilon, com malha de $1 \mathrm{~mm}$, e enterradas a cerca de $10 \mathrm{~cm}$ de profundidade. Depois de 15 e 30 dias inicialmente, e a cada mês após esse período, foram retirados quatro sacos, limpos de solo, separada a massa residual da E. densa, secada e pesada. Sacos preparados para retirada após quatro meses foram descartados porque quase não havia mais massa de E. densa e já não era possivel separar o material da planta das partículas de solo que entravam nos sacos. 
Os resultados foram submetidos à análise de variância e as médias comparadas pelo teste de Tukey a 5\% de probabilidade, usando o pacote Statistica (Statsoft, 1995). A curva da massa residual da E. densa com o tempo foi ajustada a vários modelos matemáticos, escolhendo-se o de melhor coeficiente de determinação, utilizando o mesmo pacote estatístico.

\section{RESULTADOS E DISCUSSÃO}

A massa de E. densa apresentou teor de fibras relativamente baixo e teores de carboidratos e proteínas (Tabela 1) dentro da faixa encontrada para plantas desta espécie em outros locais e que são semelhantes aos de outras macrófitas aquáticas (Corrêa et al., 2003). A baixa proporção de fibras é uma conseqüência da forma de crescimento da planta, uma aquática submersa de rápido crescimento, sem tecidos lenhosos e com alta proporção de água, características comuns na família das Hydrocharitaceae. Essas características conferem à massa das plantas uma possibilidade de rápida decomposição e liberação de nutrientes para a população microbiana decompositora (Cook \& Urmi-König, 1984).

A massa incorporada ao solo desintegrouse rapidamente, seguindo uma exponencial negativa com o tempo (Figura 1). Em um mês, a massa residual já estava reduzida a um terço da massa original e, após dois meses, era menos de $1 \%$ da original. Desse período em diante, os fragmentos porventura existentes $(<1 \%$ do original) eram tão pequenos que podiam passar pelas malhas dos sacos de decomposição, sendo difícil separá-los das partículas de solo. Velocidades de decomposição bem mais lentas têm sido verificadas para folhas de outras plantas (Sampaio et al., 1990).
Os teores dos principais nutrientes minerais na massa da E. densa (Tabela 1), como os da análise bromatológica, foram semelhantes aos de plantas desta e de outras espécies encontradas em outras represas no Sudeste do Brasil (Corrêa et al., 2003; Martins et al., 2003). Para as doses de adubação usadas, as quantidades de nutrientes adicionadas ao solo foram altas, principalmente para $\mathrm{N}$ e $\mathrm{K}$, em relação às recomendadas para milho irrigado (Cavalcanti, 1998). Na dose de $20 \mathrm{t} \mathrm{ha}^{-1}$, equivaleriam a cerca de 400,40 e $580 \mathrm{~kg} \mathrm{ha}^{-1}$ de $\mathrm{N}, \mathrm{P}$ e $\mathrm{K}$, respectivamente. Os teores dos nutrientes no esterco também ficaram na faixa usual (N, P, K, Ca e Mg foram de 9, 8, 9, 7 e $6 \mathrm{~g} \mathrm{~kg}^{-1}$, respectivamente). As quantidades de $\mathrm{P}$ aplicadas ao solo com o esterco foram quatro vezes maiores que as de E. densa (160 kg ha-1, na dose de $20 \mathrm{t} \mathrm{ha}^{-1}$ ), porém as de $\mathrm{N}$ e K foram menores, ainda que também altas (180 e $180 \mathrm{~kg} \mathrm{ha}^{-1}$, na dose de $20 \mathrm{t} \mathrm{ha}^{-1}$ ). Portanto, em todos os tratamentos, exceto na testemunha, as quantidades de nutrientes adicionadas foram altas e seus efeitos dependeriam da disponibilização dos nutrientes.

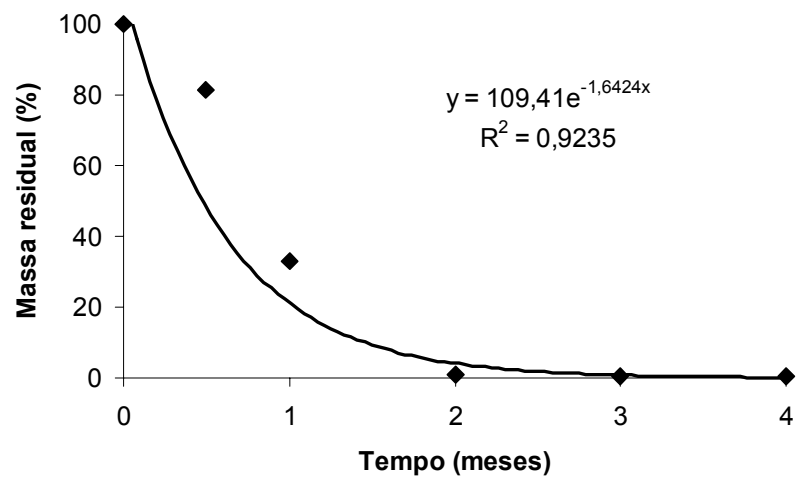

Figura 1 - Massa residual de Egeria densa após diferentes períodos de decomposição, em sacos de malha $(1 \mathrm{~mm})$ enterrados no solo.

Tabela 1 - Resultados de análises bromatológica e de elementos da massa de Egeria densa retirada do lago de Delmiro Gouveia e usada como adubo orgânico

\begin{tabular}{|l|c|c|c|c|c|}
\hline Constituinte & $\mathrm{g} \mathrm{kg}^{-1}$ & Elemento & $\mathrm{g} \mathrm{kg}^{-1}$ & Elemento & $\mathrm{mg} \mathrm{kg}^{-1}$ \\
\hline Proteína bruta & 122 & $\mathrm{~N}$ & 20 & $\mathrm{Cd}$ & 0,8 \\
\hline Extrato etéreo & 16 & $\mathrm{P}$ & 2 & $\mathrm{Cr}$ & 7,7 \\
\hline Fibras, detergente neutro & 460 & $\mathrm{~K}$ & 29 & $\mathrm{~Pb}$ & $\mathrm{C}$ \\
\hline Fibras, detergente ácido & 326 & $\mathrm{Ca}$ & 12 & $\mathrm{Co}$ & 2,3 \\
\hline Hemicelulose & 134 & $\mathrm{Mg}$ & 4 & $\mathrm{Sr}$ & 114,5 \\
\hline Cinzas & 202 & $\mathrm{~S}$ & 3 & $\mathrm{~V}$ & 9,3 \\
\hline
\end{tabular}


A produção de grãos na testemunha foi muito baixa (320 $\mathrm{kg} \mathrm{ha}^{-1}$, Tabela 2), cerca da metade da média regional (IBGE, 1998), obtida quase toda no semi-árido, em condições de sequeiro. Como a água não foi limitante, a deficiência de nutrientes deve ter sido muito aguda, justificando que a área tenha sido abandonada por estar esgotada. As produções de sabugo e palha foram compativeis com as de grãos, resultando em um índice de colheita de $21 \%$ (massa de grão/massa total), ligeiramente mais baixo que os mais usuais, em torno de 30\% (Boyer, 1996).

As produções com os adubos orgânicos foram todas relativamente altas: de 3,5 a $8,5 \mathrm{t} \mathrm{ha}^{-1}$ de grãos e de 4,3 a $8,8 \mathrm{t} \mathrm{ha}^{-1}$ de outras partes aéreas (Tabela 2). Em condições de conforto hídrico, abundância de nutrientes, alta insolação e boas temperaturas, são esperadas produções nessa faixa e até maiores, podendo atingir em condições ótimas até quase $30 \mathrm{t} \mathrm{ha}^{-1}$ (Hoeft, 2003). Analisando os quatro tratamentos como se fossem independentes, houve diferenças estatisticamente significativas (Tabela 2). Para nenhum dos dois adubos houve diferença significativa entre as doses, mas, considerando apenas os adubos, E. densa resultou em maior produção que esterco. Provavelmente, a vantagem de E. densa foi a rápida decomposição e liberação de nutrientes para o solo.

O esterco, um material já digerido, mais fibroso e com relação C:N mais ampla (cerca de 40:1, comparada à de 20:1 de E. densa), deve liberar nutrientes mais lentamente, podendo até imobilizar $\mathrm{N}$ por algumas semanas (Holanda, 1990). Naturalmente, a desvantagem de uma liberação mais lenta pode ser compensada por um fornecimento por tempo mais prolongado. Considerando a produção na dose mais baixa de incorporação de $E$. densa, os teores altos dos nutrientes que a macrófita contém e a sua rápida decomposição, é possivel que respostas semelhantes fossem obtidas com doses menores. Recomenda-se que sejam testadas as de 5 e $10 \mathrm{t} \mathrm{ha}^{-1}$. Os índices de colheita dos tratamentos adubados foram significativamente mais altos que o da testemunha, sem diferenças entre adubos e doses (44 a $49 \%)$.

Uma questão importante em qualquer adubação é a incorporação ao solo de elementos
Tabela 2 - Produção de milho ( $\mathrm{t} \mathrm{ha}^{-1}$ ) com incorporação de diferentes massas $\left(\mathrm{t} \mathrm{ha}^{-1}\right)$ de Egeria densa ou de esterco, em Neossolo Regolítico de Paulo Afonso-BA

\begin{tabular}{|l|c|c|c|c|}
\hline \multicolumn{1}{|c|}{ Tratamento } & Massa & Grão & Sabugo & Palha \\
\hline Testemunha & - & $0,3 \mathrm{~d}$ & $0,2 \mathrm{c}$ & $1,0 \mathrm{c}$ \\
\hline E.densa & 20 & $8,5 \mathrm{a}$ & $3,1 \mathrm{a}$ & $5,7 \mathrm{a}$ \\
\hline E.densa & 40 & $7,0 \mathrm{ab}$ & $2,5 \mathrm{ab}$ & $6,4 \mathrm{a}$ \\
\hline Esterco & 20 & $3,5 \mathrm{c}$ & $1,6 \mathrm{~b}$ & $2,7 \mathrm{~b}$ \\
\hline Esterco & 40 & $4,8 \mathrm{bc}$ & $2,1 \mathrm{~b}$ & $4,0 \mathrm{~b}$ \\
\hline
\end{tabular}

Médias seguidas por letras iguais, na coluna, não diferem significativamente pelo teste de Tukey a $5 \%$ de probabilidade.

indesejados. Os teores de alguns elementos determinados na massa de E. densa foram relativamente altos (Tabela 1). O cádmio, apesar de ter a menor concentração entre eles, é o mais preocupante, porque acima de um certo limite de ingestão pode causar distúrbios metabólicos graves (FAO/WHO, 2004. Teores semelhantes aos de $E$. densa têm sido encontrados em outros adubos orgânicos, especialmente compostos de lixo e lodo de esgoto (Juliatti et al., 2002; Silva et al., 2002; Oliveira et al., 2003).

Adubos fosfatados minerais podem ter teores de $\mathrm{Cd}$ muito maiores, até $170 \mathrm{mg} \mathrm{kg}^{-1}$ (Amaral-Sobrinho et al., 1992; Ramalho et al., 1999). A Environmental Protection Agency (EPA), dos Estados Unidos, estabeleceu como limite máximo, em adubos, a concentração de $85 \mathrm{mg} \mathrm{kg}^{-1}$ (Silva et al., 2002), muito acima do contido na massa de E. densa. Também estabeleceu que a incorporação ao solo não deveria elevar a concentração de $\mathrm{Cd}$ acima de $19,5 \mathrm{mg} \mathrm{kg}^{-1}$. Considerando a dose maior de incorporação usada $\left(20 \mathrm{t} \mathrm{ha}^{-1}\right)$, o teor de $\mathrm{Cd}$ presente $\left(0,8 \mathrm{~g} \mathrm{t}^{-1}\right)$ e uma camada de solo onde a massa de E. densa seria misturada de um pouco menos de $10 \mathrm{~cm}\left(1 \mathrm{t} \mathrm{ha}^{-1}\right)$, a incorporação aumentaria o teor de $\mathrm{Cd}$ do solo em apenas $0,016 \mathrm{mg} \mathrm{kg}^{-1}$, e seriam necessárias mais de 1.000 adubações seguidas no mesmo local para atingir o limite estabelecido pela EPA.

Uma característica em relação a metais pesados e ao $\mathrm{Cd}$ em especial é que sua absorção pelas raízes e translocação para a parte aérea das culturas costuma ser baixa (Juliatti et al., 2002), embora, em alguns casos, tenham sido encontrados maiores teores na parte aérea que nas raízes (Santos et al., 2002, 2003). Análises nos grãos de milho dos 
tratamentos mostraram teores em torno de $0,1 \mathrm{mg} \mathrm{kg}^{-1}$, dez vezes menores que os da massa de E. densa. Teores maiores têm sido observados em plantas de outras áreas, recebendo apenas adubação química e tratos usuais (Santos et al., 2002, 2003). O mais relevante é que os teores dos tratamentos que receberam $E$. densa $\left(0,08\right.$ a $\left.0,14 \mathrm{mg} \mathrm{kg}^{-1}\right)$ variaram em torno dos da testemunha (média de $0,10 \mathrm{mg} \mathrm{kg}^{-1}$ ) e dos que receberam esterco $\left(0,09\right.$ a $\left.0,12 \mathrm{mg} \mathrm{kg}^{-1}\right)$.

Assim, a adubação com E. densa não estaria elevando os riscos de contaminação daqueles que consumissem o milho, além dos já normalmente existentes na região. A adubação repetidas vezes no mesmo campo levaria a teores maiores no solo e, eventualmente, também nas plantas. Entretanto, admitindo os cálculos feitos anteriormente e aceitando os critérios estabelecidos pela EPA, seriam necessárias centenas de aplicações até que fosse atingido o limite crítico no solo.

Pode-se concluir que o aproveitamento, como adubo orgânico, da massa de E. densa retirada das grades das turbinas e da limpeza de reservatórios é recomendável. Dessa forma, resolve-se o problema de colocação de um material até então tratado como lixo, ao mesmo tempo em que se incorporam nutrientes ao solo e se aumenta a produção agrícola.

\section{LITERATURA CITADA}

AMARAL-SOBRINHO, N. M. B.; COSTA, L. M.; VELLOSO, A. C. X. Metais pesados em alguns fertilizantes e corretivos. R. Bras. Ci. Solo, v. 16, p. 271276, 1992.

BARRETO, R. et al. Biological control of neotropical aquatic weeds with fungi. Crop Protec., v. 19, p. 697-703, 2000 .

BOYER, J. S. Advances in drought tolerance in plants. Adv. Agron., v. 56, p. 187-218, 1996.

CAVALCANTI, F. J. A. (Coord.). Recomendações de adubação para o estado de Pernambuco: $2^{\mathrm{a}}$ aproximação. Recife: IPA, 1998. 198 p.

COOK, C. D. K.; URMI-KÖNIG, K. A revision of the genus Egeria (Hydrocharitaceae). Aquatic Bot., v. 19, p. 73-96, 1984.
CORREAA, M. R.; VELINI, E. D.; ARRUDA, D. P. Composição química e bromatológica da Egeria densa, Egeria najas e Ceratophyllum demersum. Planta Daninha, v. 21, p. 7-13, 2003. (Edição especial)

FAO/WHO. Joint FAO/WHO Expert Committee on Food Additives. Sixty-first meeting. Food and Agriculture Organization and World Health Organization of the United Nations. Disponível em: <http://www.fao.org.> e em $<$ http://www.who.int $>$. Acesso em: 25 jan. 2004.

HOEFT, R. G. Desafios para a obtenção de altas produtividades de milho e soja nos EUA. Inf. Agron., v. 104, p. 1-4, 2003.

HOLANDA, J. S. Esterco de curral: composição, preservação e adubação. Natal: EMPARN, 1990. 69 p. (Documentos, 17).

IBGE. Censo agropecuário 1995-1996. Rio de Janeiro: 1998. CD-ROM.

JULIATTI, M. A. et al. Cádmio em Latossolo Vermelho cultivado com milho em colunas: mobilidade e biodisponibilidade. R. Bras. Ci. Solo, v. 26, p. 1075-1081, 2002.

MARTINS, D. et al. Caracterização química das plantas aquáticas coletadas no reservatório de Salto Grande (Americana - SP). Planta Daninha, v. 21, p. 21-25, 2003. (Edição especial)

NASCIMENTO, P. R. F. Produção de biomassa de Egeria densa Planchon, nos reservatórios da Hidroelétrica de Paulo Afonso - Bahia. 2002. 46 f. Dissertação (Mestrado em Botânica) - Universidade Federal Rural de Pernambuco, Recife, 2002.

OLIVEIRA, C. A.; AMARAL SOBRINHO, N. M. B.; MAZUR, N. Solubilidade de metais pesados em solos tratados com lodo de esgoto enriquecido. R. Bras. Ci. Solo, v. 27, p. 171-181, 2003.

RAMALHO, J. F. G. P.; AMARAL-SOBRINHO, N. M. B.; VELlOSO, A. C. X. Acúmulo de metais pesados em solos cultivados com cana-de-açúcar pelo uso contínuo de adubação fosfatada e água de irrigação. R. Bras. Ci. Solo, v. 23, p. 971-979, 1999.

SAMPAIO, E. V. S. B. et al. Decomposição de palha de milho $\left({ }^{14} \mathrm{C}-{ }^{15} \mathrm{~N}\right)$ incorporada a três profundidades em um Latossolo Vermelho-amarelo de Pernambuco. R. Bras. Ci. Solo, v. 14, p. 269-276, 1990.

SANTOS, F. S.; AMARAL SOBRINHO, N. M. B.; MAZUR, N. Influência de diferentes manejos agrícolas na distribuição de metais pesados no solo e em plantas de tomate. R. Bras. Ci. Solo, v. 26, p. 535-543, 2002.

Planta Daninha, Viçosa-MG, v. 23, n. 2, p. 169-174, 2005 
SANTOS, F. S.; AMARAL SOBRINHO, N. M. B.;

MAZUR, N. Conseqüência do manejo do solo na

distribuição de metais pesados em um agrossistema com

feijão-de-vagem (Phaseolus vulgaris L.). R. Bras. Ci. Solo, v. 27, p. 191-198, 2003.

SILVA, J. E.; RESCK, D. V. S.; SHARMA, R. D. Alternativa agronômica para o biossólido produzido no Distrito Federal. I - Efeito na produção de milho e na adição de metais pesados em Latossolo no cerrado. R. Bras. Ci. Solo, v. 26, p. 487-495, 2002.
SILVA, W. D. O Velho Chico - sua vida, suas lendas e sua história. Brasília: MINETER/CODEVASF, 1985. $24 \mathrm{p}$.

STATSOFT. Statistica for windows, version 5.0. Copyright Statsoft. 1995.

WINTON, M. D.; CLAYTON, J. S. The impact of invasive submerged weed species on seed banks in lake sediments. Aquatic Bot., v. 53, p. 31-45, 1996. 